\title{
Pour en lire plus : Les eaux écoformatrices.
}

\section{Carine Villemagne}

\section{(2) OpenEdition}

Journals

Édition électronique

URL : http://journals.openedition.org/ere/5541

DOI : 10.4000/ere.5541

ISSN : 2561-2271

Éditeur

Centr'ERE

Référence électronique

Carine Villemagne, «Pour en lire plus : Les eaux écoformatrices. », Éducation relative à l'environnement [En ligne], Volume 4 | 2003, mis en ligne le 14 septembre 2003, consulté le 24 septembre 2020. URL http://journals.openedition.org/ere/5541 ; DOI : https://doi.org/10.4000/ere.5541

Ce document a été généré automatiquement le 24 septembre 2020. 


\title{
Pour en lire plus : Les eaux écoformatrices.
}

\author{
Carine Villemagne
}

\section{RÉFÉRENCE}

Sous la direction de Gaston Pineau et René Barbier (2001). Les eaux écoformatrices. Paris : L'Harmattan - Collection Écologie et Formation.

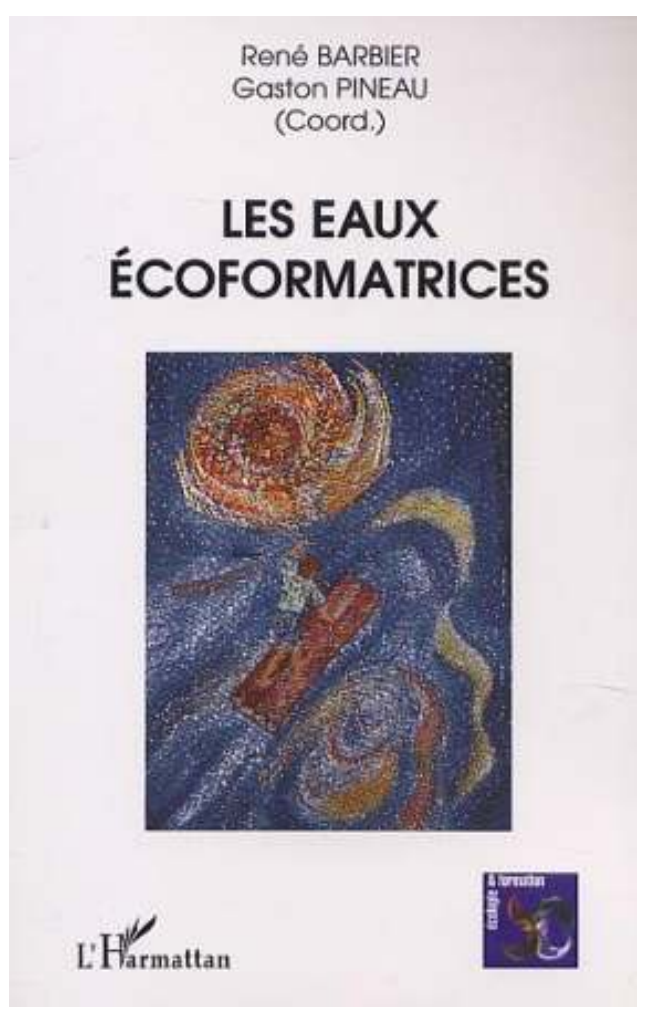


1 Cette monographie est une publication collective du Groupe de Recherche sur 1'Écoformation (GREF) sous la direction de Gaston Pineau (Université de Tours) et de René Barbier (Université de Paris VIII). Ce collectif poursuit une démarche inspirée par Gaston Bachelard visant l'exploration des quatre éléments, l'air, l'eau, la terre et le feu, et leur dimension formatrice respective pour une personne tout au long de sa vie. L'ouvrage «Les eaux écoformatrices » regroupe 19 textes où les auteurs, aux histoires personnelles et aux contextes professionnels variés, caractérisent leur lien direct ou indirect avec l'élément "eau». L'ouvrage est organisé en fonction d'une logique spécifique à la « formation tripolaire », énoncée initialement par Jean-Jacques Rousseau et enrichie par Gaston Pineau. Les trois pôles de formation permanente mis en évidence sont les suivants: soi (autoformation), les autres (hétéro-formation) et les choses (écoformation). Cette publication explore de manière privilégiée le pôle écoformation. Dominique Cottereau définit l'écoformation comme la formation personnelle que chacun reçoit par contact personnel avec le monde physique dans lequel il a grandi et dans lequel il continue de vivre.

2 Trois thèmes majeurs constituent la structure de cet ouvrage reposant essentiellement sur l'exploration de la puissance écoformatrice de l'eau présentée sous ses formes variées et ses usages multiples:

- «De soi à l'eau, genèse des relations auto-écologiques » est la première section de l'ouvrage. Elle met en évidence une centration importante de l'écoformation sur la personne: l'eau est source de formation personnelle, voilà ce qui ressort des 6 premiers chapitres. Les auteurs s'attachent à explorer la dimension trans-formatrice de la relation à l'eau par des récits de vie personnelle (voire intimes) et secondairement par des récits d'expériences professionnelles avec l'élément « eau ». Les auteurs font état des apprentissages réalisés au cours de leur vie.

- «De l'eau aux autres. Formation de relations socio-écologiques » est la deuxième section de la monographie. Elle regroupe 6 contributions d'auteurs dont les relations à l'élément " eau " s'inscrivent dans le cadre de pratiques professionnelles, celles d'éducateurs ou d'animateurs (etc.). Leurs préoccupations sont essentiellement pédagogiques: comment favoriser le dialogue d'une personne avec son milieu? Le tout rationnel semble écarté au profit d'une pédagogie reposant sur l'alternance entre découverte technico-scientifique et découverte subjective, sensorielle, symbolique et poétique du milieu entourant la personne. L'eau est aussi bien abordée dans sa globalité qu'à travers des problématiques environnementales qui lui sont associées, que par des «milieux aquatiques » particuliers, tels la mer, un fleuve ou encore la piscine!

- «L'eau entre nous. Prémices d'une éco-anthropologie» est la troisième section des «Eaux écoformatrices ». Sept chapitres présentent des pratiques et des enjeux sociaux en lien avec l'eau. Cette section propose selon les auteurs « une exploration des pistes de reconfiguration sociétale et anthropologique qu'implique la prise en compte de l'eau ».

3 Globalement, cet ouvrage collectif laisse une impression de richesse mais aussi d'hétérogénéité :

- la richesse grâce aux multiples domaines et expériences des auteurs qui ont contribué à la monographie et qui ont accepté de livrer une part de leur vécu intime avec l'eau ;

- l'hétérogénéité car, bien que la logique de l'organisation des textes soient esquissée en introduction, il est parfois ardu de la saisir au fil de la lecture. Les chapitres, comme l'a si bien souligné le préfacier, oscillent entre subjectif et objectif, entre histoire personnelle et compte rendu de recherche, entre récit descriptif et analyse théorisée. 
4 Les auteurs positionnent l'écoformation au regard de l'éducation à l'environnement. L'écoformation explore deux de ses dimensions: l'éducation PAR et DANS l'environnement. Cette contribution de l'écoformation au champ de l'éducation à l'environnement peut certes lui être reconnue. Mais surtout, cet ouvrage met en évidence certaines caractéristiques spécifiques de l'écoformation :

- Le développement de la personne, en relation avec son milieu physique, est au coeur des préoccupations de l'écoformation.

- La notion d'environnement fait référence à une conception large qui ne se limite pas à des considérations écologiques et favorise une ouverture à des expériences explorant différemment la relation à l'élément « eau ».

- La conception de la formation adoptée par les auteurs intègre le concept même d'éducation. La formation n'est pas définie par la formation professionnelle comme cela est communément admis, mais plutôt comme un processus de mise en forme globale de la personne. Par ce choix, Gaston Pineau (p. 17-18) désire indiquer aux lecteurs «que l'apprentissage par et dans l'environnement est trop complexe et vital pour s'arrêter à l'enfance ou à l'adolescence. Il est permanent et façonne silencieusement la vie d'adulte ».

5 Nous proposons deux manières de lire « les eaux écoformatrices » : choisir les chapitres qui répondent à vos préoccupations et vos questionnements ou encore vous " plonger » corps et âmes dans « les eaux » qui traversent ses 19 chapitres.

\section{AUTEUR}

\section{CARINE VILLEMAGNE}

Université du Québec à Montréal 